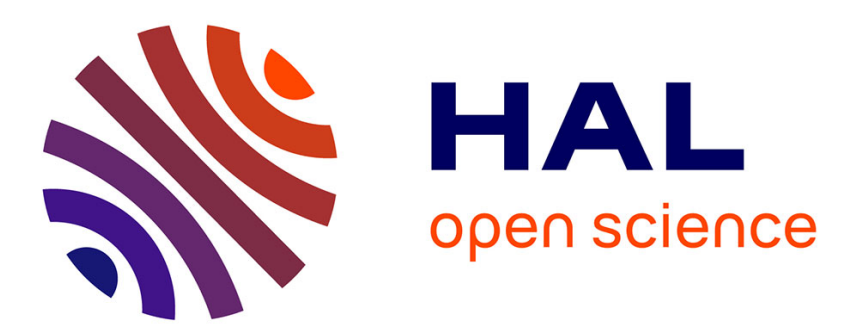

\title{
Nanoscale optical critical dimension measurement of a contact hole using deep ultraviolet spectroscopic ellipsometry
}

Houssam Chouaib, Qiang Zhao

\section{- To cite this version:}

Houssam Chouaib, Qiang Zhao. Nanoscale optical critical dimension measurement of a contact hole using deep ultraviolet spectroscopic ellipsometry. Journal of Vacuum Science \& Technology B Microelectronics and Nanometer Structures, 2012, 10.1116/1.4771969 . hal-01342905

\section{HAL Id: hal-01342905 \\ https://hal.science/hal-01342905}

Submitted on 7 Jul 2016

HAL is a multi-disciplinary open access archive for the deposit and dissemination of scientific research documents, whether they are published or not. The documents may come from teaching and research institutions in France or abroad, or from public or private research centers.
L'archive ouverte pluridisciplinaire HAL, est destinée au dépôt et à la diffusion de documents scientifiques de niveau recherche, publiés ou non, émanant des établissements d'enseignement et de recherche français ou étrangers, des laboratoires publics ou privés. 


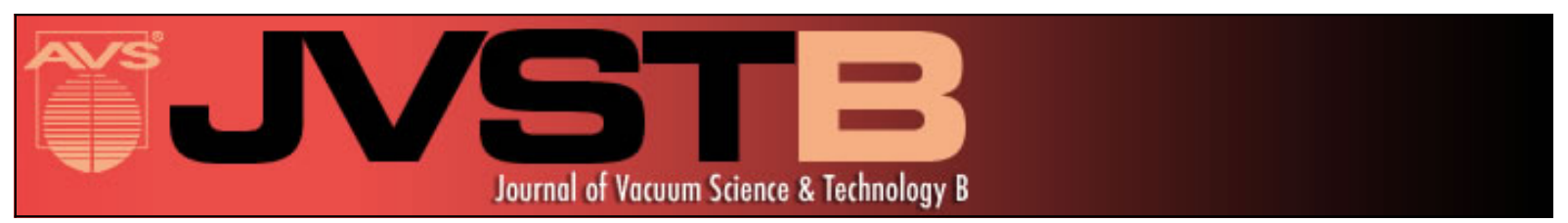

\section{Nanoscale optical critical dimension measurement of a contact hole using deep ultraviolet spectroscopic ellipsometry}

Houssam Chouaib and Qiang Zhao

Citation: Journal of Vacuum Science \& Technology B 31, 011803 (2013); doi: 10.1116/1.4771969

View online: http://dx.doi.org/10.1116/1.4771969

View Table of Contents: http://scitation.aip.org/content/avs/journal/jvstb/31/1 ?ver=pdfcov

Published by the AVS: Science \& Technology of Materials, Interfaces, and Processing

\section{Articles you may be interested in}

Investigation of the optical properties of MoS2 thin films using spectroscopic ellipsometry

Appl. Phys. Lett. 104, 103114 (2014); 10.1063/1.4868108

Influence of transfer residue on the optical properties of chemical vapor deposited graphene investigated through spectroscopic ellipsometry

J. Appl. Phys. 114, 093505 (2013); 10.1063/1.4819967

Porosity tuning of the optical properties of mesoporous silica planar defect in macroporous silica opal

J. Appl. Phys. 112, 093107 (2012); 10.1063/1.4759437

Optical characterization of $4 \mathrm{H}-\mathrm{SiC}$ by far ultraviolet spectroscopic ellipsometry

Appl. Phys. Lett. 79, 162 (2001); 10.1063/1.1384895

Normal-incidence spectroscopic ellipsometry for critical dimension monitoring

Appl. Phys. Lett. 78, 3983 (2001); 10.1063/1.1378807

\section{HDDEN}

\section{Instruments for Advanced Science}

w www.HidenAnalytical com

w www. HidenAnalytical.com E info@hiden.co.uk

CLICK TO VIEW our product catalogue

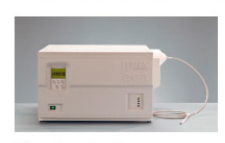

Gas Analysis

, dynamic measurement of reaction gas streams catalysis and thermal analysis , molecular beam studies , molecular beam studies , dissolved species probes

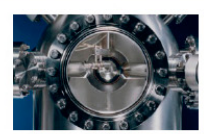

Surface Science

, UHVTPD

, SIMS , end point detection in ion beam etch
, elemental imaging - surface mapping

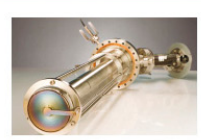

Plasma Diagnostics , plasma source characterization etch and deposition process reaction , kinetic studies , analysis of neutral and radical species

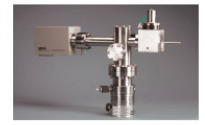

Vacuum Analysis , partial pressure measurement and control of process gases reactive sputter process control , yaum dagnostics 


\title{
Nanoscale optical critical dimension measurement of a contact hole using deep ultraviolet spectroscopic ellipsometry
}

\author{
Houssam Chouaib ${ }^{\text {a) }}$ and Qiang Zhao \\ KLA-Tencor Corporation, 1 Technology Drive, Milpitas, California 95035
}

(Received 12 March 2012; accepted 29 November 2012; published 19 December 2012)

\begin{abstract}
Highly sensitive optical metrology techniques based on spectroscopic ellipsometry (SE) are required for three dimensional monitoring of line-profiles and critical-dimension (CD) of advanced design-rule devices. In this paper, theoretical and SE-based experimental techniques are used to study elliptical contact holes $(\mathrm{CH})$ in a $\mathrm{SiO}_{2}$ layer. These structures were chosen because measuring their shapes is made difficult by the low optical contrast between air inside the holes and $\mathrm{SiO}_{2}$, as well as the strong coupling between critical shape parameters. Results showed that moving from conventional ultraviolet SE to deep ultraviolet SE (DUVSE) was a key to breaking the correlation between top and bottom $\mathrm{CD}$ and obtaining an accurate and physically realistic $\mathrm{CH}$ profile. The DUVSE-based CD results were validated using a scanning electron microscope. @ 2013 American Vacuum Society. [http://dx.doi.org/10.1116/1.4771969]
\end{abstract}

\section{INTRODUCTION}

As semiconductor manufacturing progresses toward the $22 \mathrm{~nm}$ node, ${ }^{1-3}$ where geometrically complex structures are incorporated, a rapid, nondestructive, and accurate critical dimension (CD) metrology system becomes more necessary. Precise measurement of the sizes and shapes of nanoscale features in semiconductor devices is a critical part of manufacturing process control to ensure that the structures are being built to specifications.

Optical critical dimension (OCD) methods are emerging as alternative methods to scanning electron microscope (SEM) for inline metrology, especially in production. Highly precise, accurate, and nondestructive, OCD is becoming widely used for applications such as shallow trench isolation, ${ }^{4}$ gate after develop inspection, ${ }^{5,6}$ after etch inspection, ${ }^{6}$ final inspection, ${ }^{5}$ high-k metal gate applications, ${ }^{5}$ and recess gate control. $^{7}$

Conventionally, SEM and atomic force microscopy (AFM) have been used for these measurements. However, besides the charging artifacts which can obscure detail on SEM images, these methods suffer from disadvantages such as low throughput, material damage, limited sensitivity, and poor repeatability.

In addition to spectroscopic ellipsometry, OCD can incorporate other optical methods, the best known of which are angle-resolved ellipsometry and broadband reflectometry. ${ }^{8}$

For some challenging structures, applying more than one technology can be beneficial. The criteria for choosing one method over another include the geometry and dimensions of the structure; the number of variable parameters (floating degrees of freedom) in the model used to describe the structure, the materials' optical dispersions $(\mathrm{n}(\lambda)$ and $\mathrm{k}(\lambda))$, optical contrasts among materials comprising the structure, feature sizes, etc. These factors affect the sensitivity of the results to changes in parameters and the ability to distinguish the effects of changes in one parameter from changes in

\footnotetext{
a) Author to whom correspondence should be addressed; electronic mail: houssam.chouaib@kla-tencor.com
}

another (correlation). High parametric sensitivity and low correlation are desirable.

The OCD techniques must be wisely chosen in order to optimize parametric sensitivity, increase measurement precision, and eliminate the correlation to other parameters. Sensitivity and correlation analysis are usually simulated and performed prior to the experimental measurements to predict the optimized method. One advantage of using the spectroscopic ellipsometry (SE)-OCD methods is the wide range of "knobs" available for measurement optimization, including the angle of incidence (AOI), the analyzer angle (AA), the azimuth angle (AZ), ${ }^{9}$ and the wavelength range. Adjusting these parameters can be critical to OCD measurement performance. For example, the direction from which the light hits the target (the azimuth angle) can have a great impact on the sensitivity and the precision of the measurement. KLA-Tencor's new SpectraShape systems offer a diverse array of optical technologies to enable comprehensive and rapid characterization of a wide range of structures. Patented algorithms combine and analyze the multiple signals to produce a detailed description of the shape of an IC feature and identify any deviations beyond allowed tolerances.

The subject of this paper is the full characterization of a three-dimensional contact hole profile. It is shown that adding deep ultraviolet (DUV) illumination to the SE spectrum improves parametric sensitivity and eliminates the correlation between top and bottom CD. As a result, the hole ellipticity, the undercut distance, and the layer thicknesses can be accurately measured. SE-OCD comparison to SEM data is also presented.

\section{MEASUREMENT TECHNOLOGY}

The OCD measurements presented in this paper were performed on a SpectraShape 8810 dimensional metrology system using its SE subsystem. OCD SE technology analyzes the polarization state of the reflected light by rotating a polarizer and using a fixed analyzer. ${ }^{8}$ For each measurement, the two standard ellipsometry spectra are simultaneously collected, $\tan \Psi(\lambda)$ and $\cos \Delta(\lambda)$, which are derived from the 


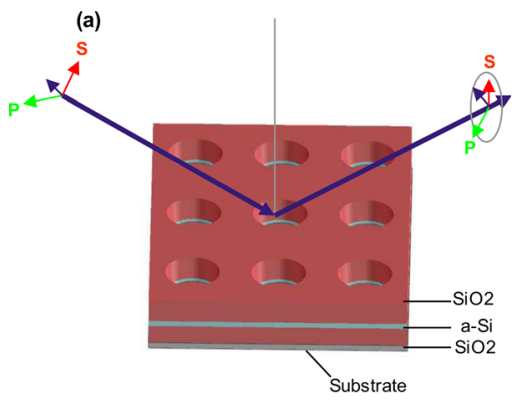

(b)

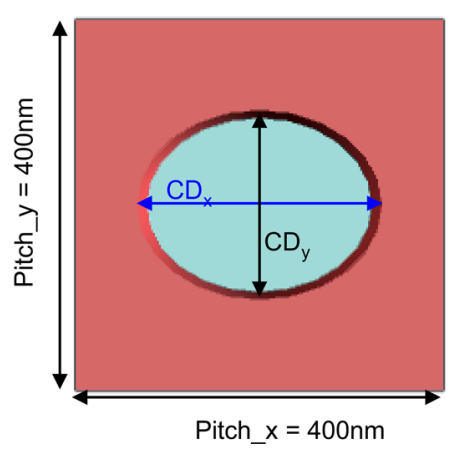

FIG. 1. (Color online) (a) Isometric view of the contact hole target, including an illustration of the incident and reflected SE beam. (b) Top view of the single unit cell contact hole model. The pitch is $400 \mathrm{~nm} \times 400 \mathrm{~nm}$.

wavelength variation of the intensity, $\Psi$, and phase difference, $\Delta$, of the elliptical polarized reflected light.

$\operatorname{Tan} \Psi(\lambda)$ and $\cos \Delta(\lambda)$ can be represented mathematically as

$$
\tan \Psi \cdot \exp (\mathrm{i} \Delta)=\frac{r_{p}}{r_{s}}=\frac{\left|r_{p}\right|}{\left|r_{s}\right|} \cdot \exp (i \Delta),
$$

where $r_{p}$ is the component of the reflected electric field having polarization parallel to the plane of the incident and reflected beams, and $r_{s}$ is the component having polarization perpendicular to that plane.

In the metrology tool used for this study, the SE subsystem measures the reflected light intensity as a function of polarizer angle and wavelength for a fixed analyzer angle A. ${ }^{8}$ Thus, it is useful to transform $\tan \Psi(\lambda)$ and $\cos \Delta(\lambda)$ to the quantities $\alpha_{\mathrm{m}}(\lambda)$ and $\beta_{\mathrm{m}}(\lambda)$, where

$$
\alpha=\frac{\tan ^{2}(\Psi)-\tan ^{2}(A)}{\tan ^{2}(\Psi)+\tan ^{2}(A)}
$$

and

$$
\beta=2 \cos (\Delta) \frac{\tan (\Psi) \tan (A)}{\tan ^{2}(\Psi)+\tan ^{2}(A)} .
$$

SE-OCD is a model-based technique, requiring a valid and robust theoretical model. Spectra are measured on a grating, and results are determined by comparing the measured data with a theoretical model, using either a regression algorithm or a library constructed using neural network training. Model development requires prior knowledge of the periodic grating including geometry and optical properties of current and underlying layers, including the $\mathrm{n}$ and $\mathrm{k}$ dispersions of all materials, linewidths, sidewall angles (SWA), line heights, layer thicknesses, etch depths, etc. The quality of the model relies on the accuracy and completeness of the description of the structure to be measured.

The periodic grating will not only reflect but also diffract light, and the return beam of light can be concentrated in angular directions which are not readily predictable. Therefore, rigorous coupled wave analysis (RCWA) ${ }^{10-12}$ is performed on the collected spectra in order to calculate the electromagnetic field strengths in the vicinity of the grating and then determine the thicknesses and the dimensions of the structure.

\section{DESCRIPTION OF SAMPLES AND SEM MEASUREMENTS}

Contact hole OCD targets were fabricated on silicon wafers. First, a layer of silicon dioxide $\left(\mathrm{SiO}_{2}\right)$ of $90 \mathrm{~nm}$ nominal thickness was deposited on the silicon substrate, followed by a thin amorphous silicon (a-Si) layer of $26 \mathrm{~nm}$ nominal thickness. Then another $\mathrm{SiO}_{2}$ layer was formed on top with a nominal thickness of $110 \mathrm{~nm}$. An elliptical $\mathrm{CH}$ was then created whose profile was defined using four parameters: depth, top $\mathrm{CD}_{\mathrm{x}}(\mathrm{TCD})$, bottom $\mathrm{CD}_{\mathrm{x}}(\mathrm{BCD})$, and ellipticity $=\mathrm{CD}_{\mathrm{x}} / \mathrm{CD}_{\mathrm{y}}$. The $\mathrm{CH}$ depth equals the sum of the top $\mathrm{SiO}_{2}$ layer thickness and the a-Si layer thickness.

The resulting 3D structure had a pitch of $400 \mathrm{~nm} \times 400 \mathrm{~nm}$, periodically patterned onto a $50 \mu \mathrm{m} \times 50 \mu \mathrm{m}$ test pad. In order to simulate process drift in a real manufacturing situation, four targets with different ellipticities $(1,1.1,1.25,1.45)$ were constructed. Figure 1 shows (a) an isometric model view and (b) a top view of the targets.

SEM images of the four targets 1, 2, 3, 4 as well as topdown cross-section scanning electron microscopy (XSEM) image are shown in Figs. 2(a)-2(e), respectively. SEM-based measurements generated ellipticities slightly different from the
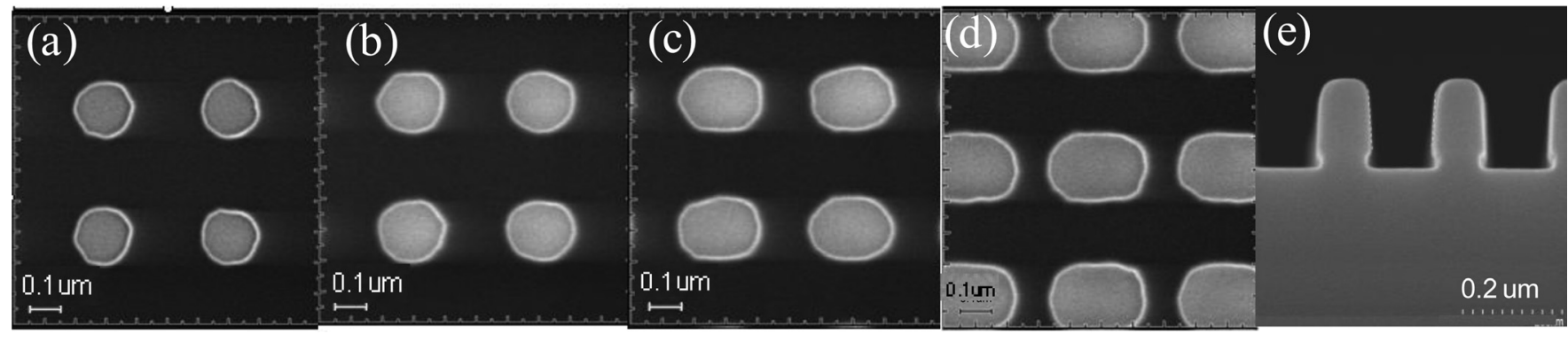

FIG. 2. Top-down CD-SEM images of the four targets: (a) target 1: nominal ellipticity $=1$; (b) target 2: nominal ellipticity $=1.1$; (c) target 3 : nominal ellipticity $=1.25$, (d) target 4 : nominal ellipticity $=1.45$. (e) The top-down XSEM image showing the nonvertical obtuse SWA $\left(\right.$ angle $\left.>90^{\circ}\right)$. 


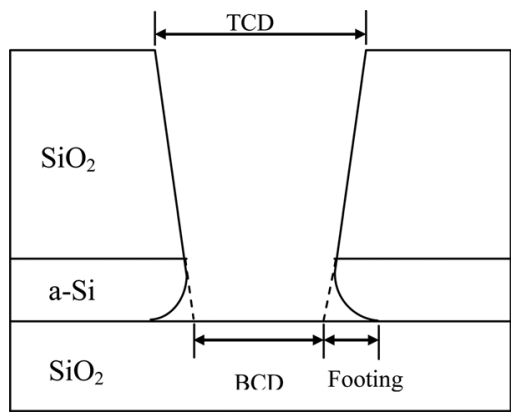

FIG. 3. Line profile cross section of the contact hole. The schematic illustrates the TCD and BCD and B_Footing parameters used in the model.

nominal values: $1.02 / 164,1.13 / 195,1.29 / 242$, and 1.40/290 for targets $1,2,3$, and 4 . Note that the white border around the contact holes in the SEM images suggests that the SWA were not vertical. This claim is validated by the SEM cross-section image of Fig. 2(e), showing the nonvertical (TCD > BCD) SWA.

\section{DEEP UV SE ANALYSIS AND SIMULATION}

In addition to the elliptical $\mathrm{CH}$ profile parameters (ellipticity, TCD, and BCD), four additional floating parameters were included in the model: the bottom oxide height (B_HT), the bottom footing parameter (B_Footing), the amorphous silicon height (a_HT), and the top oxide height (T_HT). The B_Footing parameter is defined by a pair of circular arcs tangential to the bottom surface of the patterned trench and the two adjacent linearized sidewall edges of the line as illustrated in Fig. 3. The dispersion curves $(\mathrm{n}(\lambda)$ and $\mathrm{k}(\lambda)$ ) of silicon dioxide and amorphous silicon were predetermined and were not allowed to vary in the initial model.

One challenge we faced with this structure is the low $\mathrm{SiO}_{2}$ refractive index and the lack of the optical absorption in the UV-to-visible range. Figure 4 shows the dispersion curves of $\mathrm{SiO}_{2}$ in the $160-750 \mathrm{~nm}$ range. While the extinction parameter $\mathrm{k}$ is nearly 0 for the most of the spectrum, the refractive index slightly varies slightly as a function of wavelength, 1.45 at $750 \mathrm{~nm}, 1.52$ at $235 \mathrm{~nm}$, and 1.652 around $160 \mathrm{~nm}$. Note that below $300 \mathrm{~nm}$, the slope clearly increases and so does the contrast between oxide and air.

In cases of low contrast materials such as oxide and air, in which the difference between the two refractive indices

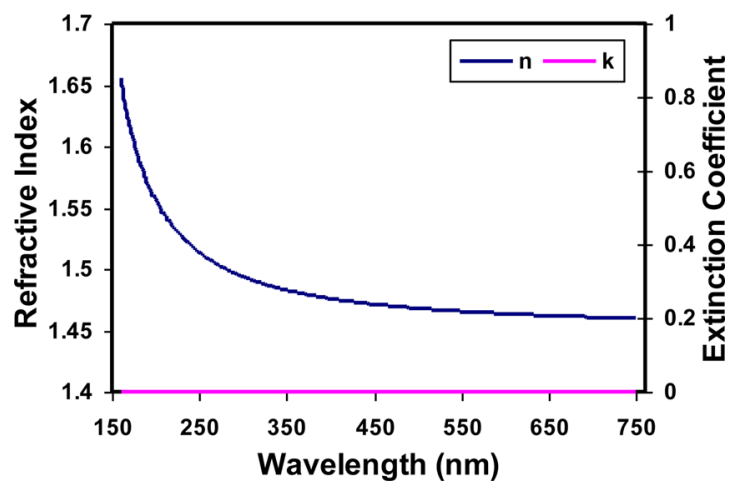

FIG. 4. (Color online) Refractive index $\mathrm{n}$ and extinction coefficient $\mathrm{k}$ for $\mathrm{SiO}_{2}$.
$(\Delta \mathrm{n})$ is low, the top and bottom $\mathrm{CH} C \mathrm{CD}$ are expected to be strongly correlated. ${ }^{13}$ A possible outcome is that SE could report a $\mathrm{CH} C D$ offset $(\triangle \mathrm{CD}=\mathrm{TCD}-\mathrm{BCD})$ that represents an unrealistic profile; for example, the top $\mathrm{CD}$ could be smaller than the bottom CD, inconsistent with the SEM results.

In order to highlight the TCD/BCD correlation issue, a set of simulated SE spectra with two different $\mathrm{CH}$ profiles were generated prior to the actual experimental measurements. From these, the alpha and beta SE spectra [see Eqs. (2) and (3)] were calculated and plotted in the UV-visible range of $235-750 \mathrm{~nm}$ to simulate the tool's standard ultraviolet SE (UVSE) subsystem spectral response. Two sets of TCD/BCD values were used in the simulation: $T C D=195 \mathrm{~nm} /$ $\mathrm{BCD}=185 \mathrm{~nm}$ and $\mathrm{TCD}=185 \mathrm{~nm} / \mathrm{BCD}=195 \mathrm{~nm}$. The first profile represents a $\mathrm{CH}$ with an obtuse SWA. The second case, however, is an unrealistic profile with an acute $\mathrm{CH}$ SWA. For the remaining five parameters, the nominal values were used: B_HT $=90 \mathrm{~nm}$, a_HT $=26.5 \mathrm{~nm}, \mathrm{~T} \_H T=110 \mathrm{~nm}$, ellipticity $=1.3$, B_Footing $=10 \mathrm{~nm}$.

As expected, because of the low refractive index of $\mathrm{SiO}_{2}$ in the $235-750 \mathrm{~nm}$ spectral range, there is little difference between the UVSE spectra (Fig. 5) for the two cases, even though there is a significant variation in the $\mathrm{CH}$ profile. The nearly indistinguishable spectra indicate highly correlated TCD/BCD parameters.

Since the $\mathrm{SiO}_{2}$ refractive index rises at short wavelengths, as shown in Fig. 4, the oxide/air contrast $(\Delta \mathrm{n})$ would be enhanced - and the top and bottom CD correlation should be reduced-if we were to use data from the DUV part of the spectrum. For this purpose, another set of simulated SE spectra was generated in the wavelength range of $160-235 \mathrm{~nm}$, using the same conditions as the UVSE simulation described
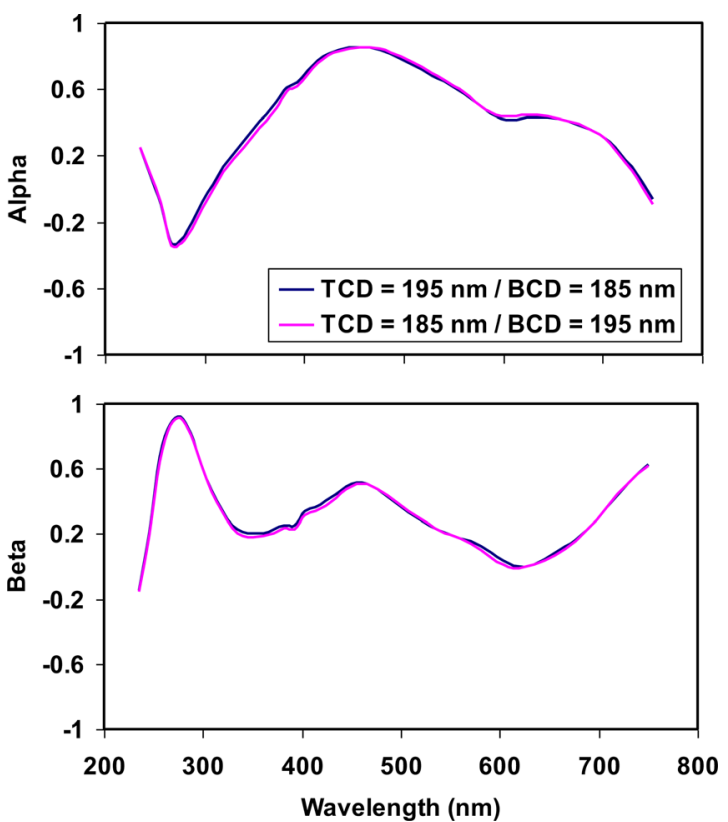

FIG. 5. (Color online) Alpha and beta spectra calculated and plotted in the UV-visible range of $235-750 \mathrm{~nm}$ to simulate our standard UVSE subsystem spectral response. Two set of top $\mathrm{CD}$ /bottom $\mathrm{CD}$ values were used in the simulation: $\mathrm{TCD}=195 \mathrm{~nm} / \mathrm{BCD}=185 \mathrm{~nm}$ and $\mathrm{TCD}=185 \mathrm{~nm} / \mathrm{BCD}=195 \mathrm{~nm}$. 
above. Figure 6 shows the simulated deep ultraviolet SE (DUVSE) spectra. Similar to the UVSE spectra in Fig. 5, the DUVSE spectra are nearly identical from 235 to $172 \mathrm{~nm}$. However, below $172 \mathrm{~nm}$, the spectra become distinctly separate, indicating a break in the $\mathrm{BCD} / \mathrm{TCD}$ correlation. Based on this theoretical analysis, we expected that using DUV wavelengths would enhance the oxide/air contrast and the measurement accuracy of the $\mathrm{CH}$ profile.

\section{EXPERIMENTAL RESULTS}

Experimental UVSE and DUVSE data were collected from the four targets having varying ellipticities. For each target, nine different locations were measured. Examples of the UVSE (235-750 nm) and DUVSE (235-160 nm) spectra are shown in Figs. 7 and 8, for data recorded from the edge point of the wafer (target 3 with nominal ellipticity $=1.25$ ). Spectra were fitted using the seven floating parameter model of Sec. IV. Standard $\mathrm{n}$ and $\mathrm{k}$ dispersions were used for the $\mathrm{Si}$ substrate, the $\mathrm{SiO}_{2}$ layers, and the a-Si layer.

In order to experimentally validate the advantage of using DUVSE for this $\mathrm{CH}$ structure, two subsequent regressions, with and without DUVSE data, were performed. When only the UVSE (235-750 nm) range was considered, the parameters were found to be $\mathrm{SiO}_{2} \mathrm{~B} \_\mathrm{HT}=(91.12 \pm 0.03) \mathrm{nm}$, a_HT $=(26.41 \pm 0.01) \mathrm{nm}, \mathrm{SiO}_{2} \mathrm{~T} \_\mathrm{HT}=(105.83 \pm 0.03) \mathrm{nm}$, ellipticity $=(1.278 \pm 0.001), \mathrm{BCD}=(194.85 \pm 0.16) \mathrm{nm}, \mathrm{TCD}$ $=(194.15 \pm 0.17) \mathrm{nm}, \mathrm{B} \_$Footing $=(8.09 \pm 0.05) \mathrm{nm}$. BCD is slightly greater than TCD $(\triangle C D=-0.7 \mathrm{~nm})$ and the SWA $=89.8^{\circ}$. Such a physically unrealistic result (TCD $<\mathrm{BCD}$ or SWA $<90$ ) is due to a high correlation between the fit variables. As expected from our calculated spectra, the regression routines of the UVSE spectra alone were unable to distinguish between the effects of the two variables. The
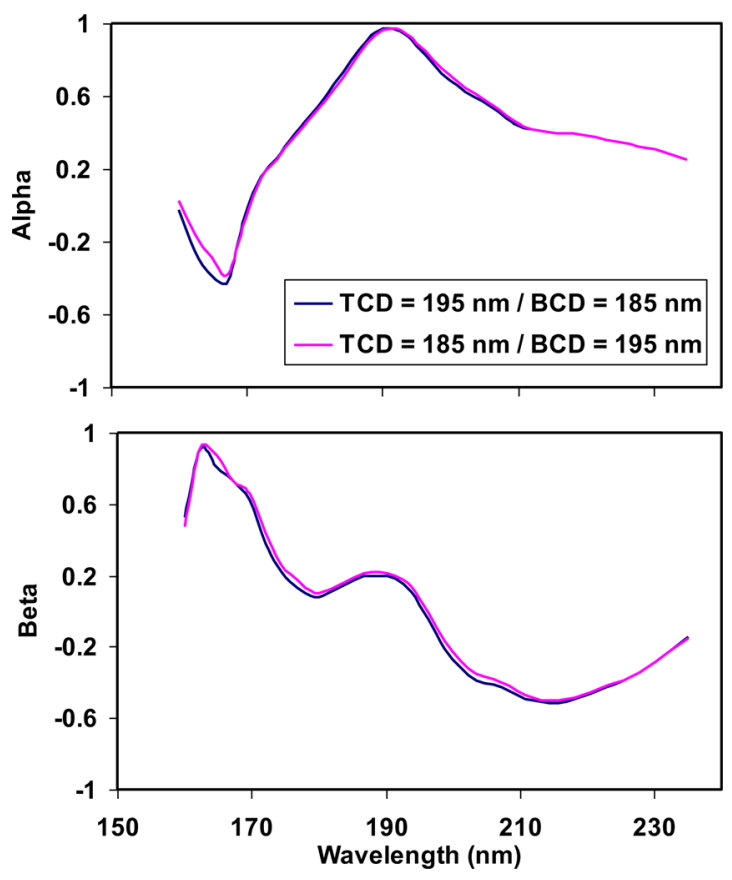

FIG. 6. (Color online) Similar to Fig. 4, calculated DUVSE spectra in the wavelength range of $160-235 \mathrm{~nm}$.
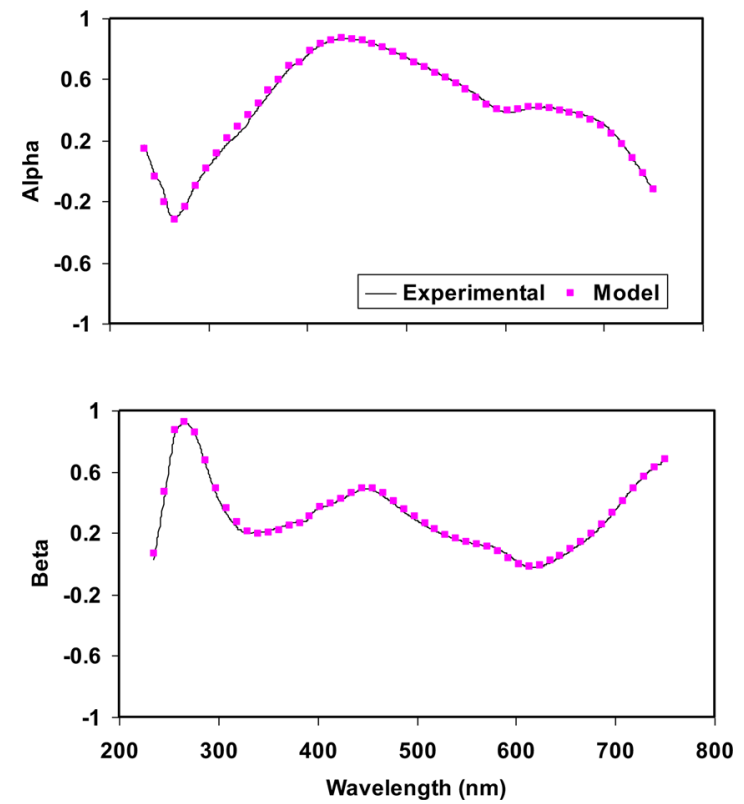

FIG. 7. (Color online) Experimental and regressed model UVSE spectra of one measured site- target 3 .

goodness of fit $(\mathrm{GOF})^{8}$ is evaluated as an average chi-squared value of 238 .

When the DUVSE data were included in the regression (Fig. 8), the parameters were found to be $\mathrm{SiO}_{2}$ B_HT $=(91.01 \pm 0.03) \mathrm{nm}, \quad$ a_HT $=(26.41 \pm 0.01) \mathrm{nm}, \quad \mathrm{SiO}_{2}$ T_HT $=(106.20 \pm 0.03) \mathrm{nm}$, ellipticity $=(1.280 \pm 0.001), \mathrm{BCD}$ $=(193.16 \pm 0.16) \mathrm{nm}, \mathrm{TCD}=(196.71 \pm 0.17) \mathrm{nm}$, B_Footing $=(8.16 \pm 0.05) \mathrm{nm}$. The results reveal a more accurate $\mathrm{CH}$ profile and a physically realistic obtuse angle (TCD $>$ BCD) consistent with the SEM images of Fig. 2(e). $\triangle \mathrm{CD}$ is now $3.55 \mathrm{~nm}$ and the $\mathrm{SWA}=90.8^{\circ}$ for this particular site of target 3 .
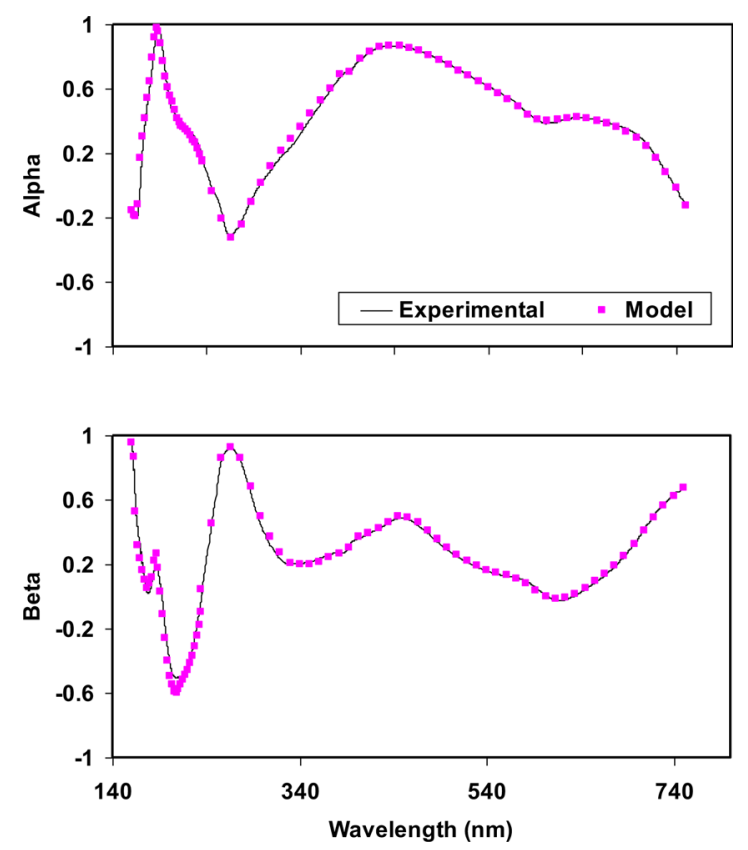

FIG. 8. (Color online) Experimental and regressed model combined UVSE + DUVSE spectra of one measured site- target 3 . 
Figure 9 shows the contact hole $\mathrm{TCD} / \mathrm{BCD}$ regression results of 36 sites ( 9 sites per target) (a) with and (b) without DUVSE. While the wafer trend was consistent among the four targets as well as between both measurements (UVSE and UVSE + DUVSE), the $\mathrm{CH} \triangle \mathrm{CD}=\mathrm{TCD}-\mathrm{BCD}$ deviances (or, equivalently, the sidewall angles) were broader when the DUVSE measurements were included. DUVSE decreased the BCD and increased the TCD of the $\mathrm{CH}$ compared to the UVSE data. However, it is worth noting that the DUVSE spectra had little impact on the thickness values of the three layers. The percent shift of $\mathrm{SiO}_{2}$ B_HT was $-0.12 \%$ : a_HT shifted by $0.00 \%$; $\mathrm{SiO}_{2}$ T_HT shifted by $0.34 \%$, and B_Footing shifted by $0.80 \%$. Furthermore, the combined DUVSE and UVSE model resulted in an improved GOF compared to the simple UVSE only. The average chi-squared distribution (for goodness of fit) from the 36 sites was 172.

Finally, our model-based SE results were compared to CD-SEM results. Figures 10(a) and 10(b) compare the OCD ellipticity and linewidth averaged over nine sites for each of the four targets versus the average ellipticity measured from SEM. The nondestructive optical results are consistent with the SEM results with a small systematic offset. A straight trend line regression is applied to evaluate the quality of the correlation between the OCD and SEM data. The ellipticity (CDx) correlation between both techniques is excellent. $\mathrm{R}^{2}$ is $0.9997(0.9998)$ and the slope is 0.9882 (1.0002), very close to unity. The small offset between SEOCD and SEM might be due to the different sources of errors in the techniques, including, for instance, the different repeatability and reproducibility values of the tools and OCD model input conditions.
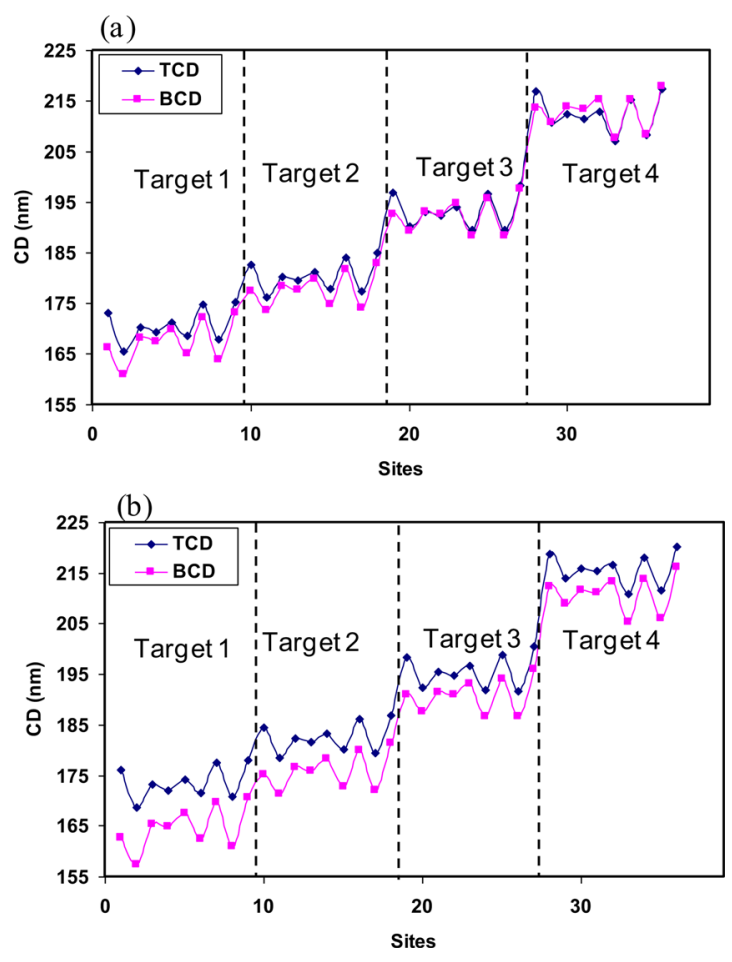

FIG. 9. (Color online) Measured SE TCD and BCD for all 36 sites (9 sites/ target) using (a) UVSE only and (b) combined UVSE + DUVSE.
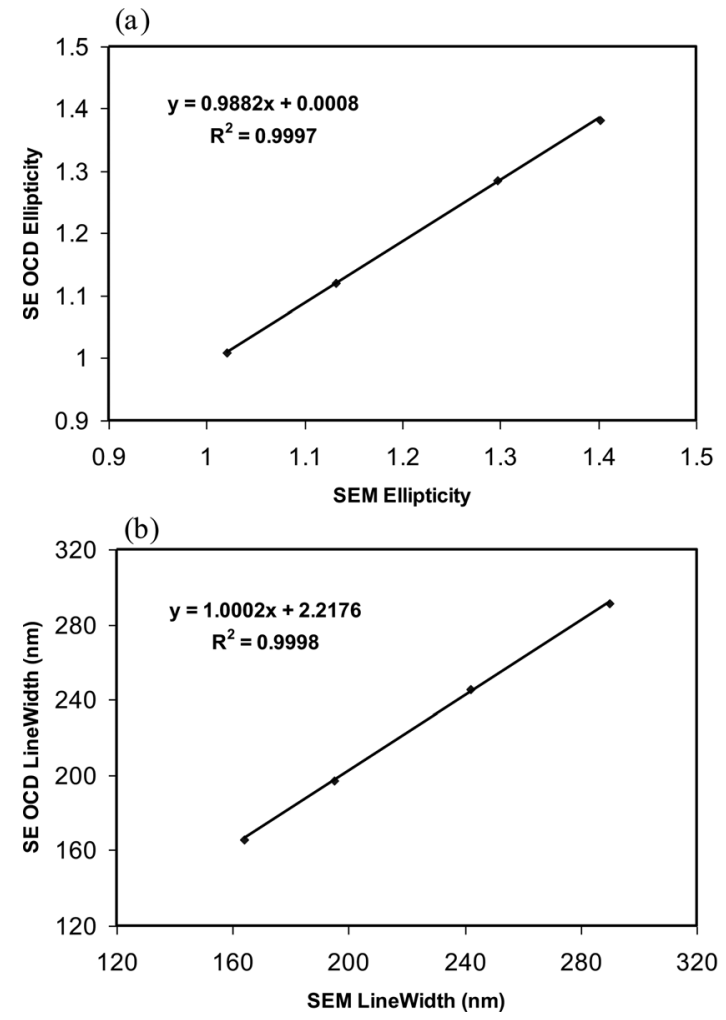

FIG. 10. Correlation between measurements using SE OCD and SEM.

\section{SUMMARY AND CONCLUSION}

Nondestructive and accurate OCD shape metrology can be valuable for inline process control of the IC feature geometries. In this study, spectroscopic ellipsometry was used to characterize the three-dimensional shape of a contact hole in $\mathrm{SiO}_{2}$. Four elliptical contact hole targets were developed, modeled, simulated, and optically measured. The calculated spectra in the wavelength range from 235 to $750 \mathrm{~nm}$ (UVSE) revealed that the bottom CD and the top CD parameters were highly correlated due to the similarity in optical dispersion of $\mathrm{SiO}_{2}$ and air. However, when DUV wavelengths (160-235 nm) were added, analysis of the calculated spectra predicted that the parametric correlation would be broken and OCD would provide a more reliable contact hole shape.

SE measurements were performed at nine sites across the wafer for each target. As the simulations predicted, the $\mathrm{CH}$ shape extracted from the regression of the UVSE data was physically unrealistic for few sites. By including DUV wavelengths in the measurements, however, the SE results produced an accurate and realistic $\mathrm{CH}$ profile. The combined DUV/UV SE system resulted in an improved goodness of fit, compared to the UV SE system alone. The results were validated by a comparison to CD-SEM. An excellent linear correlation with the SEM was demonstrated for the ellipticity and linewidth of the contact holes.

${ }^{1}$ E. Karl, Y. Wang, Y.-G. Ng, Z. Guo, F. Hamzaoglu, U. Bhattacharya, K. Zhang, K. Mistry, and M. Bohr, Solid-State Circuits Conference Digest of Technical Papers (ISSCC 2012) (IEEE, San Francisco, 2012), p. 230. 
${ }^{2}$ Y. Cohen et al., Proc. SPIE 7971, 79711N (2011).

${ }^{3}$ B. Bunday, V. Vartanian, L. Ren, G. Huang, C. Montgomery, W. Montgomery, A. Elia, and X. Liu, Proc. SPIE 7971, 797120 (2011).

${ }^{4}$ C.-H. Lin et al., Proc. SPIE 8324, 832421 (2012).

${ }^{5}$ A. Vaid, M. Sendelbach, S. Komarov, T. Dziura, J. Ferns, and J. Madsen, Proceedings of the 21 st Annual IEEE/SEMI Advanced Semiconductor Manufacturing Conference (ASMC) (IEEE, San Francisco, 2010), p. 341.

${ }^{6}$ W.-J. Tzai et al., Proc. SPIE 8324, 832420 (2012).

${ }^{7}$ M.-F. Kuo, S.-H. Wu, T.-H. Lan, S.-H. Chang, E. Wang, H. Chouaib, H. Cheng, and Q. Zhao, Proc. SPIE 8324, 83241Z (2012).
${ }^{8}$ Handbook of Silicon Semiconductor Metrology, edited by A. C. Diebold (CRC, New York, 2001), p. 723.

${ }^{9}$ M. Sendelbach, A. Vaid, P. Herrera, T. Dziura, M. Zhang, and A. Srivatsa, Proc. SPIE 7638, 76381G (2010).

${ }^{10}$ M. G. Moharam, T. K. Gaylord, G. T. Sincerbox, H. Werlich, and B. Yung, Appl. Opt. 23, 3214 (1984).

${ }^{11}$ M. G. Moharam and T. K. Gaylord, J. Opt. Soc. Am. 71, 811 (1981).

${ }^{12}$ R. Antos, J. Pistora, J. Mistrik, T. Yamaguchi, S. Yamaguchi, M. Horie, S. Visnovsky, and Y. Otani, J. Appl. Phys. 100, 054906 (2006).

${ }^{13}$ T. Novikova, A. De Martino, S. Ben Hatit, and B. Drevillon, Appl. Opt. 45, 3688 (2006). 